\title{
DUSST: Development of a new stress sweep fatigue test for asphalt
} mixtures.

3

4 5 6 (1)

\section{Abstract}

Fatigue cracking is one of the main damage mechanisms that take place in asphalt pavements. However, its evaluation during the design stages of the asphalt mixtures is not usually considered due to the complexity of the tests required, their high costs and the long time needed to perform them. As a consequence, several research teams have been working on developing new test procedures to reduce the time and costs related to the fatigue characterization of asphalt mixtures. In this context, this paper presents the development of a new test procedure that consists of cyclic uniaxial tension-compression test in which the stress applied increases every 5,000 cycles. This way it is possible to evaluate the response of the mixture under cyclic loading at different stress levels in one test, and the failure of the mixture takes place in a shorter period of time than that required by the classical time sweep fatigue tests. This paper presents the results obtained in the application of this new methodology to a mixture frequently used in Chilean pavement structures (type IV-A-12 by Chilean standards) with three different asphalt binders, a conventional binder (CA-24), a high modulus binder (CAHM) and a polymer-modified binder (CA-PM). Also, three different types of aggregates, obtained by two different shredding processes, were evaluated. The results achieved in the development of this Direct Uniaxial Stress Sweep Test (DUSST) show that it is a practical method with great potential. It allows fatigue behavior of asphalt mixtures at a shorter time to be characterized by means of important parameters, such as initial strain, failure strain, complex modulus and dissipated energy. In addition, a good sensitivity of the DUSST main parameters to variables evaluated was obtained.

Keywords: Asphalt mixture; Fatigue test; Stress sweep test; Dissipated energy; Fatigue behavior.

\footnotetext{
*Corresponding author. E-mail addresses: gonzalo.valdes@ufrontera.cl Telephone contact: (+56-45) 2325680
} 


\section{INTRODUCTION}

The most basic form of travel between 2 points in a country corresponds to roads and highways. These are key to a country's economic and social development [1], [2]. As a reference, approximately 95\% of road and highway pavements around the world correspond to asphalt pavements [3]. Additionally, pavement structure is the part of the road infrastructure which requires the greatest investment of economic resources, both in the construction and maintenance stages [4]. Furthermore, the pavement state directly influences the majority of indirect highway costs. These costs increase when the pavement state is not optimal, mainly due to increases in travel times, fuel consumption, and deterioration of transportation vehicles, among others [5], [6]. In the case of asphalt mixtures, the main performance properties that should be considered during dosage and design phases are: 1) resistance to plastic deformations, 2) resistance to raveling due to damage caused by moisture, 3) resistance to thermal stress cracking, and 4) resistance to fatigue cracking. This last property refers to the resistance that an asphalt mixture must present when subjected to the dynamic and repetitive solicitations caused by traffic loads. In this aspect, it is important to highlight that distress caused by fatigue cracking of the asphalt mixture layers is one of the main damage mechanisms that take place in asphalt pavements [7], [8]. The accelerated progress of fatigue cracking involves serious economic implications, mainly due to the need to rehabilitate or rebuild pavement structure before the estimated time, thus increasing the cost of infrastructure at the time of use. Additionally, this distress has an aesthetic effect when rehabilitation is not carried out in the indicated period, or when only minor maintenance is done. Finally, there is an effect on comfort for road users, which also affects their safety due to possible structure detachments when deterioration is greater [5], [9]. Fatigue cracking is caused by tensile and compressive forces produced by the traffic loads on the pavement, leading to the progressive reduction of asphalt mixture stiffness modulus [10]. In a pavement structure, when the vehicle wheel loads are relatively far from the considered cross section, a tensile force is produced at the top of the layer and a compressive force is produced at the bottom, Fig 1a. Then, when the load is on top of the considered section, the stress state changes, and a compressive force is produced at the top of the layer while a tensile force is produced at the bottom. After the load passes, the stress state reverses again [11]. This effect is continuously repeated with the passing of each vehicle over the pavement. In this context, asphalt mixtures work as a dual system of mechanical resistance: on one hand, during compression the friction between the mineral particles oppose its relative displacement, on the other 
hand, during tension the binder and interlocking of aggregates resist the stresses. For these reasons, good adhesion between the aggregates and binder (even in the presence of water) and sufficient internal cohesion in the mixture (so that the binder does not break) are the properties desired for a good performance of the asphalt mixtures [12].

In the traditional approach to fatigue cracking in asphalt mixtures, bottom-up cracking is considered. That is, micro-cracks are caused by deformations from tensile stresses originated in the lower part of the asphalt layer, causing the beginning of the crack and its propagation towards the surface. Regarding this, the repetition and accumulation of loads generate cracking and the consequent failure due to pavement fatigue, despite stresses generated are lower than the tensile stress limit of the material [13], [14]. In addition to the traditional approach, there are also several studies indicating that there is a top-down cracking mechanism which collaborates in fatigue cracking produced by thermal variations and by heavy vehicles with high tire inflation pressure, thus generating tensile and shear stresses on the pavement surface [15], [16].

As a consequence of the traffic loads asphalt mixtures accumulate damage, which results in a gradual cracking process instead of a sudden process of brittle failure. From this point of view, the validity of Miner's Law is often supported for fatigue analysis, establishing that each applied load generates fatigue consumption, and that these consumptions accumulate until the fatigue resistance of the mixture is exhausted [17], [18], [19]. In this context, Kanitpong and Bahía pointed out that during the fatigue process, the continuous loss of resistance and degradation of the asphalt mixture is a result of the formation of initial microcracks and the consequent accumulation of damage that achieves the total degradation of the material [20]. This concept is expressed more clearly by Baaj and Di Benedetto, who noted that the fatigue degradation process of an asphalt mixture can be established in three phases, which are: 1) phase I or adaptation phase, which is characterized by the beginning of microcracking, producing a sharp decrease in the dynamic modulus, which is not only attributed to a fatigue phenomenon, but rather to a combined phenomenon resulting from material thixotropy and initial heating due to the test's application of cyclic loading, 2) phase II or fatigue phase, is mainly characterized by fatigue deterioration in the damage evolution of the mixture. Macrocracks resulting from the union of microcracks generated in phase I appear. This phase is characterize by a linear decrease of the stiffness with the number of cycles. Finally, 3) phase III or failure phase, in which the macrocracks quickly progress until the total failure of the asphalt mixture occurs [21]. 
Nowadays, asphalt mixtures' resistance to fatigue cracking is determined in the laboratory by applying repeated loading to specimens [8], [22]. These procedures consist of conducting cyclic tests at constant stress or strain amplitude, and using the classic failure criterion. This failure criterion, as described in the European standard UNE-EN 12697:24, establishes failure of the specimen when its stiffness reduces half of the initial value. In the case of displacement or strain-controlled tests, the failure of the specimen is assumed when the initial load $\left(\mathrm{F}_{0}\right)$ is reduced by half $\left(\mathrm{F}_{0} / 2\right)$, and in the case of force or stress-controlled tests, failure of the specimen is assumed when the strain $\left(\varepsilon_{0}\right)$ is equal to double the initial strain $\left(2 \varepsilon_{0}\right)$ [23]. However, one of the disadvantages that arise in these procedures is that their failure criteria provide erroneous results when testing very flexible asphalt mixtures, manufactured using a high content of asphalt binder or modified binders. These flexible mixtures can experience a 50\% reduction in their stiffness only due to reversible phenomena, and therefore not fail if solicitation is reduced or completely stopped [24]. This is explained due to a readjustment of the materials into the mixture, mainly due to material viscoelasticity. A combined effect of thixotropy and heating may exist due to the application of dynamic loads; once the application of these dynamic loads has finished, the material recovers part of its condition or original state [25], [26], [27], [28]. It has also been observed that when stress-controlled determination tests are conducted, fatigue failure takes place at the same strain level regardless of the level of applied stress [29]. This indicates that there is a strain level at which each asphalt mixture fails under cyclic loading in stress-controlled tests. This strain would correspond to the strain amplitude that would cause failure in few cycles in cyclic strain-controlled tests. Moreover, there is a stress level below which the mixture presents elastic behavior and the applied loads do not produce any distress process [17], [30], [31]. In this context, it is very important to know these two strain levels to characterize the behavior of the material under cyclic loading: 1) the level that does not produce damage, and 2) the level which causes total failure in few load applications.

In relation to the procedures that are used to characterize resistance to fatigue cracking in asphalt mixtures, these present some drawbacks which cause that the fatigue property of asphalt mixtures is usually not considered in asphalt mixtures design. The main one being that these tests require extended periods of time for test execution and numerous tests (and specimens) to characterize the material (e.g. the UNE EN 1269724 standard requires 6 replicates to be tested at three strain amplitudes, a total of 18 replicates) [32]. To overcome this, some testing procedures or prediction models have been developed recently to predict fatigue 
behavior of asphalt mixtures in a shorter period of time [8], [33], [34], [35]. An example is the Fenix

117 procedure. Using some of the parameters obtained in this test procedure, a fatigue law can be estimated [36].

118 Another procedure that provides a faster way of obtaining an estimation of the fatigue law of the asphalt mixtures is the EBADE test [37], [38], which is based on a strain sweep imposed on a notched prismatic specimen. This procedure accelerates the damage process in the material by increasing the strain applied,

121 providing an overall view of its behavior under cyclic loading at different strain amplitudes in a single test. Although these methodologies (Fenix and EBADE) are good procedures to estimate the fatigue response of asphalt mixtures in the short term, a better procedure could be developed keeping in mind that, 1) the Fenix test was designed to evaluate mechanical cracking resistance of asphalt mixtures in the face of static load application at direct tension (it is not a dynamic fatigue test), and whose correlations were obtained for a specific number of asphalt mixtures in specific environmental conditions [36], and 2) a study carried out by Tangella et al. that indicated the stress-controlled fatigue tests present advantages over strain-controlled tests, including: lower dispersion of results, shorter time test execution and the results reflect a greater influence of the mixture characteristics, among others [39].

The purpose of the present paper is to present the application of a new stress sweep fatigue test method developed at the University of La Frontera, called DUSST (Direct Uniaxial Stress Sweep Test), with the aim of improving the main drawbacks related to the conventional and non-traditional test methods and its failure criteria, previously described. This fatigue test method tries to represent the main stress state at which the asphalt mixture is subjected in the pavement structure.

\section{DUSST TEST DEVELOPMENT}

The Direct Uniaxial Stress Sweep Test (DUSST) simulates the cyclical tension-compression stresses that occur both in the surface area and at the base of the asphalt layers of the pavement, Fig.1a. To this end, cylindrical specimens are manufactured by extraction of a cylindrical core with a diameter of $50.8 \mathrm{~mm}$ (2 inches), from samples fabricated by standard manufacturing methods, such as the Marshall method or the gyratory compactor. It can also be obtained from field cores extracted from the pavement. The cylindrical 
the extracted core are cut to produce parallel faces and a diametric notch of $5 \mathrm{~mm}$ deep and $4 \mathrm{~mm}$ wide is made in the central area. Its height, which can range from 60 to $120 \mathrm{~mm}$, depends on the diameter of the test piece or field core of origin (often 100 or $150 \mathrm{~mm}$ ), Fig 1b. For the execution of the test, the specimen must be fixed between two metal plates, which must be parallel between their faces for the correct axial application of the forces. Then, the specimen is fixed to a dynamic press and two sensors that are used to record the deformations of the specimen during the execution of the test, Fig 2a. On the specimen, a series of 5000 cycles of incremental stresses is applied uniaxially with a sinusoidal traction-compression signal in each cycle, Fig 2d. For each cycle the level of deformation of the specimen is recorded. This is done until the test piece breaks due to fatigue. This rupture occurs in the area of the specimen previously notched due to the higher stress concentration, Fig $2 \mathrm{~b}$ and Fig 2c. Throughout the test period, the evolution of the module and the energy dissipated are recorded. The test can be carried out at different frequencies and temperatures. For this procedure, two levels of deformation, that define the fatigue behavior of the mixture, have been established [32]. The failure strain $\left(\varepsilon_{\mathrm{f}}\right)$ is defined as that which would cause the failure of the material in few load applications and is measured as the double of the average strain recorded during the cycles 100 and 500 of each loading stage. The initial strain $\left(\varepsilon_{\mathrm{i}}\right)$ is defined as the one that would produce the failure in a very high number of load applications (associated with the endurance limit). This strain value is obtained as the average strain of the previous step to that in which the difference of the average of strain between cycles 100 and 500 , and cycles 4600 and 5000, is less than 10\%, Fig. 3.

\subsection{DUSST parameters}

During the test load and vertical displacement are measured constinuosly and from them stress $(\sigma)$ in $\mathrm{MPa}$, strain $(\varepsilon)$, norm of the complex modulus $\left(\left|\mathrm{E}^{*}\right|\right)$ in MPa and dissipated energy density (DED) in $\mathrm{J} / \mathrm{m}^{3}$ are computed using equations (1-4):

$$
\sigma=\frac{F}{A_{f}}
$$

$$
\varepsilon=\frac{\Delta L}{A f} \cdot\left(\frac{L i}{1013.42}+\frac{4}{A f}\right),
$$




$$
\left|E^{*}\right|=\frac{\sigma_{\max }}{\varepsilon_{\max }}
$$

170

$$
\mathrm{DED}=\frac{1}{2}\left|\left(\sigma_{1} \varepsilon_{2}+\sigma_{2} \varepsilon_{3}+\cdots+\sigma_{\mathrm{n}-1} \varepsilon_{\mathrm{n}}+\sigma_{\mathrm{n}} \varepsilon_{1}\right)-\left(\sigma_{2} \varepsilon_{1}+\sigma_{3} \varepsilon_{2}+\cdots+\sigma_{\mathrm{n}} \varepsilon_{\mathrm{n}-1}+\sigma_{1} \varepsilon_{\mathrm{n}}\right)\right| \cdot 10^{6}
$$

171 where, $F$ is the force in $\mathrm{N}, A_{f}$ is the area of the notched section of the specimen in $\mathrm{mm}^{2}, \Delta \mathrm{L}$ is the change in length, $L i$ is the half of the measurement length less the half of the notch length, $\sigma_{\max }$ is the stress amplitude in a cycle, $\varepsilon_{\max }$ is the strain amplitude recorded during the same cycle, $\sigma_{\mathrm{i}}$ and $\varepsilon_{\mathrm{i}}$ are the $n$ values of stress and strain recorded within the cycle $i$.

\section{EXPERIMENTAL STUDY}

176

The purpose of this section is to show the application of the DUSST procedure as well as the results that can be obtained from it. The experimental plan and the materials used during this investigation are described. The results obtained and their implications regarding the fatigue behavior of the mixtures studied are presented. Finally, a statistical analysis to evaluate the sensitivity of the parameters delivered by the proposed procedure is presented.

\subsection{Materials and testing plan}

In this study, the DUSST procedure was applied to five semi-dense asphalt mixtures type IV-A-12 (according to the Chilean specification), whose granulometry is shown in Fig 4. Three types of asphalt binders and three types of aggregates were evaluated. The asphalt cements used corresponded to a conventional binder, CA-24; an SBS polymer modified binder, CA-PM; and a high modulus asphalt binder, CA-HM, which is characterized by its low penetration and by being used for the manufacture of high modulus mixtures, Table 1. The aggregates used were 2 fluvial type (AF1 and AF2) and one coming from quarry (AC). The fluvial type aggregates were obtained from the same place and they are mainly composed of dolomite, basalt, dacite, andesite, rhyolite, sandstone, quartz and quartzite. The quarry aggregate AC is composed mainly of quartz, biotite and iron oxide. The only difference between fluvial aggregates is the crushing process. AF1 was obtained by means of a cone crusher and AF2 was obtained by an impact crusher. The AC aggregates were obtained by means of a cone crusher. The characteristics of the aggregates used can be seen in Table 2 .

The asphalt mixtures used to evaluate the effect of the type of binder were manufactured with the aggregate AF1, while those employed to evaluate the effect of the type of aggregate were fabricated using the 
conventional binder CA-24. The optimum binder content for all mixtures evaluated was $5.2 \%$ on aggregates weight, and it was obtained by means of Marshall Design Method, according to Chilean specifications. The dimensions of the DUSST specimens used in this study were $50.8 \mathrm{~mm}$ in diameter, $60 \mathrm{~mm}$ in height and a notch in the central area of $4 \mathrm{~mm}$ in height and $5 \mathrm{~mm}$ in depth. These DUSST specimens were extracted from $100 \mathrm{~mm}$ diameter cylindrical samples manufactured by the Marshall method. The test routine consisted in the application of series of cycles of different stress amplitudes, with a duration of 5,000 cycles each. It started with a stress amplitude of $250 \mathrm{kPa}$ and the amplitude was increased by $50 \mathrm{kPa}$ every 5,000 cycles until the material failed. Three specimens were evaluated for each type of mixture, the frequency of the stress input signal was $10 \mathrm{~Hz}$ during the whole test and the test temperature was $20^{\circ} \mathrm{C}$. The strain amplitude, the norm of the complex modulus $\left|E^{*}\right|$, the dissipated energy density, DED, the failure strain and the initial strain were obtain for each specimen. To evaluate the sensitivity of the procedure in relation to the variables type of binder and type of aggregate, an ANOVA analysis of variance was performed. For each parameter delivered by the DUSST test, a variance analysis of one factor with several samples per group was performed. For these analyzes the factors evaluated were: type of binder and type of aggregate. The binder type factor consisted of three levels corresponding to the three binders analyzed (CA24, CA PM, CA HM), while for type factor of aggregate, consisted of three levels (AF1, AF2 and AC).

\section{ANALYSIS OF THE RESULTS}

\subsection{Evolution of strains}

Figure 5 shows the evolution of the strain during the tests for the mixtures manufactured with different binders. The strain increased gradually, showing higher slopes as the stress applied increased until the specimens failed. The mixture made with the polymer-modified binder, CA-PM, showed greater ductility, showing higher initial and failure strains than the mixtures manufactured with CA-24 and CA-HM. In addition, it recorded a greater number of cycles until the material failed, indicating that it resisted a higher stress amplitude. On the other hand, the more rigid mixture manufactured with the high modulus binder, CA$\mathrm{HM}$, registered low levels of initial and failure strains $\left(\varepsilon_{\mathrm{i}}\right.$ and $\left.\varepsilon_{\mathrm{f}}\right)$, with the smallest difference between these two values. Therefore, the slope change in the strain vs. cycle curve between stress levels was very small. The mixture made with the conventional binder CA 24 showed a more ductile behavior than the high modulus one, showing higher initial and failure strains. 
224 Unlike other standardized procedures, the DUSST was able to show clearly the strain amplitude at which the 225 asphalt mixture fails in stress-controlled cyclic testing, regardless of the stiffness of the mixture. The two strain values obtained in the test $\left(\varepsilon_{\mathrm{i}}\right.$ and $\left.\varepsilon_{\mathrm{f}}\right)$ can be related with the fatigue law of the mixture. The initial strain is related with a strain level at which the mixture could endure millions of cycles in a conventional time sweep test, i.e., the endurance limit. Regarding the failure strain, this value should be related with the strain at which the mixture would reach failure in a few thousand cycles in time sweep test. Previous research using strain sweep test [Botella, R., Pérez-Jiménez, F.E., Miro, R., Martínez, A.H. New methodology to estimate 231 the fatigue behavior of bituminous mixtures using a strain sweep test (2017) Construction and Building Materials, 135, pp. 233-240. López-Montero, T., Miró, R., Botella, R., Pérez-Jiménez, F.E. Obtaining the fatigue laws of bituminous mixtures from a strain sweep test: Effect of temperature and aging (2017) International Journal of Fatigue, 100, pp. 195-205.] showed failure strain correlated fairly well with the strain level that produced failure in time sweep tests in 10,000 cycles, and that fatigue laws obtained in time sweep tests predicted 10 million cycles for strains close to the failure strain. Following this line of research, time sweep tests results were analyzed and compared with the DUSST results leading to the conclusion that the initial strain obtained from DUSST corresponds to 5,000 cycles and the failure strain to 50 million cycles in time sweep tests at those strain levels. Therefore, a rough approximation to the fatigue law of the material was extracted from the DUSST results pairing 5,000 cycles with the initial strain and 50 million cycles with the failure strain. The fatigue laws obtained by this methodology are shown in figure 5.

Regarding the influence of the aggregate type, table 3 shows the average parameters obtained in the DUSST for each mixture. These results show that the mixture manufactured with the aggregate with the highest form factor and lowest slab index (AF2), Table 2, obtained greater number of cycles until failure, showing a higher initial strain, but failed at lower failure strain. Conversely, the mixture with the aggregate with the highest rate of slabs and the lowest values registered in the form factor and fine particle index (AC) presented a lower durability. The mixture made with the aggregate AF1 with intermediate values in its form factor, slab index and Fine particle index, recorded an intermediate durability, but with a greater difference between the values of initial and failure strain. 


\subsection{Evolution of complex modulus}

252 The evolution of the complex modulus $(|\mathrm{E} *|)$ during the test is shown in Figure 6. The most rigid mixture,

253 manufactured with the CA-HM binder, obtained the highest initial modulus value (| E * i), 10,790 MPa. In

254 this case, the material behaves elastically to a high level of stress, but its degradation occurs more abruptly

255 than the other mixtures evaluated. On the contrary, the value of the initial complex modulus of the mixture

256 made with the polymer-modified binder (CA-PM) was 4,600 MPa. Figure 6 shows that for this mixture the

257 deterioration was continuous and progressive as the stress level increased, but without an abrupt failure.

258 Además, registró la menor pendiente de daño del material entre las mezclas evaluadas. The mixture with the

259 conventional binder CA-24 showed an intermediate behavior, with an initial complex modulus value (|E* $\left.\left.\right|_{\mathrm{i}}\right)$ of

260 6,788 MPa. A continuous decrease of stiffness was observed during the test. Regarding the influence of the

261 aggregate type (Table 3), it is observed that the mixtures with the highest value of Coarse particle index

262 (Table 2) obtained higher initial complex modules $\left(\left|E^{*}\right|_{i}\right)$, which agrees with what was expressed in a

263 previously published study [40].

\subsection{Evolution of dissipated energy}

The dissipated energy during each cycle was computed as the area of the hysteresis loop that forms in the stress-strain plane. As the stress amplitude applied increased, also did the strain amplitude, and therefore the hysteresis loop area and the dissipated energy. The dissipated energy density recorded in each cycle $\left(\mathrm{DED}_{\mathrm{c}}\right)$ and the accumulated dissipated energy density during the whole test $\left(\mathrm{DED}_{\mathrm{a}}\right)$ are shown in figure 7 . The values obtained from accumulated dissipated energy $\left(\mathrm{DED}_{\mathrm{a}}\right)$ were $9,791 \mathrm{MJ} / \mathrm{m}^{3}, 2,817 \mathrm{MJ} / \mathrm{m}^{3}$ and $0.543 \mathrm{MJ} / \mathrm{m}^{3}$ for the mixtures manufactured with the binders CA-PM, CA-24 and CA-HM, respectively. The mixture that showed the best behavior is the one manufactured with the polymer modified binder, CA-MP, dissipating around 18 times more energy in the whole fatigue process than the more rigid mixture with the CA-HM binder and almost 3.5 times more than the mixture made with the conventional binder CA-24. Regarding the aggregate type study, it was observed that those mixtures with higher number of cycles to failure (AF1 and AF2) obtained the highest values of accumulated dissipated energy $\left(\mathrm{DED}_{\mathrm{a}}\right)$. However, among them, a mixed effect between ductility and durability was observed, which led to similar values of accumulated dissipated energy (DEDa), Table 3. The accumulated dissipated energy parameter ( $\left.D E D_{a}\right)$, defined in the DUSST test method, is considered an important and promising parameter to characterize the fatigue behavior of the 
asphalt mixtures, since it provides a relation between the work required to achieve the failure of the mix and the degree of ductility that it has.

\subsection{Statistical analysis of results}

Sensitivity of the DUSST test was evaluated by a variance analysis (ANOVA) of the results for the most relevant parameters obtained in the experimental tests. With ANOVA it is possible to find out whether the values of a set of numerical data are significantly different from those of other sets. Thus, test sensitivity for a specific parameter can be determined. In a first stage, test sensitivity of the IV-A-12 mixture to binder type was analysed from the results obtained for the initial strain $\left(\varepsilon_{\mathrm{i}}\right)$, failure strain $\left(\varepsilon_{\mathrm{i}}\right)$, complex modulus $\left(\left|\mathrm{E}^{*}\right|_{\mathrm{i}}\right)$ and dissipated energy $\left(\mathrm{DED}_{\mathrm{a}}\right)$. A variance analysis of one factor (i.e., binder type) was conducted with several samples per group. Binder type levels were CA-24, CA-PM and CA-HM, with three data for each level. As can be seen at the top of the Table 4, the F-Value for binder type factor for all evaluated parameters are greater than their critical values determined for a significance level of 0.05 . This means that for the binder type, significantly different values are obtained for the evaluated DUSST parameters. Thus, test sensitivity to the factor analysed at this stage is determined. Analogously, in a second stage, test sensitivity of the IV-A-12 mixture to aggregate type was analysed for the same DUSST parameters. As in the previous stage, a variance analysis of one factor (i.e., aggregate type) was carried out with several samples per group. Aggregate type levels were AC, AF1 and AF2, with three data for each level. From the Table 4, it can concluded that, for aggregate type, significantly different values of most of the evaluated parameters are obtained in the DUSST tests. Thus, test sensitivity to the factor analysed at this stage is determined.

\section{CONCLUSIONS}

The following conclusions can be drawn from the results of this study:

1. The DUSST proved to be a practical method with great potential to characterize fatigue behavior of asphalt mixtures in a shorter time as far as variables such as binder type and aggregate type are concerned. In addition, this test can be used on laboratory specimens and on field cores.

2. The DUSST produced important parameters to characterize the fatigue behavior of asphalt mixture, such as: initial strain, failure strain, complex modulus and dissipated energy. Moreover, it provided 

as being ductile or stiff.

3. A fatigue law estimation was proposed using the DUSST. This test does not seek to replace the cyclic tests to obtain fatigue test laws. Rather, it proposes a new tool to quickly estimate the fatigue behavior of asphalt mixtures. results of the main parameters of the new test procedure.

\section{ACKNOWLEDGEMENTS}

314 The present paper is the result of the research supported by Universidad de la Frontera program, conducted 315 within the framework of the Project DI18-0053. 


\section{REFERENCES}

[1] T. Keane, "The economic importance of the national highway system," Public Roads, vol. 59, no. 4, 1996.

[2] H. Ibarrola, "La importancia de la infraestructura carretera en el desarrollo económico de un país.," Rutas, pp. 2-3, 2008.

[3] Asphalt Institute, The Asphalt Handbook. MS-4. 7th edition., USA: Asphalt Institute, 2007.

[4] Y. Huang, Pavement Analysis and Design (2nd Edition), New Yersey: Pearson Prentice Hall, 2004.

[5] H. De Solminihac, Gestión de Infraestructura Vial, Santiago: Pontificia Universidad Católica de Chile, 2001.

[6] F. Pérez, R. Miró and A. Martínez, Proyecto y conservación de carreteras., Barcelona: Asociación Española de la Carretera., 2006.

[7] H. Di Benedetto, C. De la Roche, H. Baaj and A. Pronk, "Fatigue of bituminous mixtures: different approaches and RILEM group contribution.," in Sixth international RILEM Symposium on Performance Testing and Evaluation of Bituminous Materials, Zurich, 2003.

[8] F. Moreno and M. Rubio, "UGR-FACT test for the study of fatigue cracking in bitumninous mixes.," Construction and Building Materials, vol. 43, pp. 184-190, 2013.

[9] G. Valdés, F. Pérez, R. Miró, A. Martínez and J. Amoros, "Desarrollo de un nuevo ensayo experimental para la evaluación de la resistencia a tracción directa y la energía disipada en el proceso de fractura en mezclas asfálticas.," in XV CILA Congreso Iberoamericano del Asfalto, Lisboa, 2009.

[10] K. Mollehauer and M. Wistuba, "Fatigue effect in uniaxial cyclic stress test: The link between stiffness decrease and accumulation of irreversible strain.," in 7th International RILEM Symposium on Advanced Testing and Characterization of Bituminous Materials, Greece, 2009.

[11] C. Racanel, M. Romanescu, M. Dicu, A. Burlacu and C. Surlea, "Fatigue lines for asphalt mixtures used in wearing course.," Advanced Testing and Characterization of Bituminous Materials, vol. 2, pp. 795805, 2009.

[12] F. Moreno, Diseño de un método de ensayo de laboratorio para el análisis de la resistencia a fisuración 
de mezclas bituminosas utilizadas en la construcción de firmes de carretera., Granada: Tesis Doctoral. Universidad de Granada., 2012.

[13] F. Pérez, R. Miró, A. Martínez, J. Alonso, J. Cepeda and M. Rodríguez, Desarrollo de un nuevo procedimiento para la evaluación del comportamiento a fatiga de las mezclas bituminosas a partir de su caracterización en un ensayo a tracción., Madrid: Premio Internacional a la Innovación en Carreteras Juan Antonio Fernández del Campo., 2005.

[14] R. Brown, P. Kandhal and J. Zhang, "Performance testing for hot mix asphalt. NCAT Report 01-05.," National Center for Asphalt Technology., Auburn, 2001.

[15] D. Harmelink and T. Aschenbrener, "xtent of top-down cracking in Colorado, Report No. CDOT-DTDR-2003-7.," Colorado Department of Transportation., Denver, 2003.

[16] H. Yared, D. Jelagin and B. Birgisson,, "Mechanics-based top-down fatigue cracking initiation prediction framework for asphalt pavements.," Road Materials and Pavement Design, vol. 16, pp. 907927, 2015.

[17] S. Carpenter, "Fatigue Performance of IDOT Mixtures. Research Report FHWA-ICT-07-007.," Illinois Center for Transportation, Rantoul, 2006.

[18] J. González, J. Canet, S. Oller and R. Miró, "A viscoplastic constitutive model with strain rate variables for asphalt mixtures- numerical simulation," Computacional Material Science, vol. 38, pp. 543-560, 2006.

[19] R. Lugmayr, M. Jamek and E. Tshegg, "Mechanism of fatigue crack growth and fracture behavior in bituminous roads," Advanced Testing and Characterization of Bituminous Materials, vol. 2, pp. 807-816, 2009.

[20] K. Kanitpong and H. Bahia, "Relating adhesion and cohesion of asphalts to the effect of moisture on laboratory performance of asphalt mixtures," Transportation Research Record, vol. 1901, pp. 33-43, 2005.

[21] H. Baaj and H. Di Benedetto, "Effect of binder characteristics on fatigue of asphalt pavement using an intrinsic damage approach.," Road Materials and Pavement Design, vol. 6, pp. 147-174, 2006. 
[22] S. Zhi, W. Gun, L. Hui and T. Bo, "Evaluation of fatigue crack behavior in asphalt concrete pavements with different polymers modifiers.," Construction and Building Materials, vol. 27, pp. 117-125, 2012.

[23] J. Alonso, Estudio del proceso de deformación y agrietamiento por fatiga de mezclas bituminosas sometidas a carga cíclica., Barcelona: Tesis Doctoral. Universidad Politécnica de Cataluña., 2006.

[24] F. Pérez, R. Miró, A. Martínez, R. Botella, O. Reyes and G. Valdés, "False failure in flexural fatigue tests.," in 2nd Workshop on 4 PB - Four Point Bending, Guimaraes, 2009.

[25] J. Mewis and N. Wagner, "Thixotropy.," Advances in Colloid and Interface Science, vol. 147, pp. 214227, 2009.

[26] F. Pérez, R. Botella and R. Miró, "Damage and thixotropy in asphalt mixture and binder fatigue tests," Transportation Research Record: Journal of the Transportation Research Board, no. 2293, pp. 8-17, 2012.

[27] R. Botella, F. Pérez, E. Riahi, T. López, R. Miró and A. Martínez, "Importancia de los periodos de reposos en el comportamiento bajo cargas cíclicas de los materiales bituminosos," in XIX Congreso Ibero Latinoamericano del Asfalto, Medellín, 2017.

[28] F. Pérez, R. Botella, R. Miró and A. Martínez, "Analysis of the thixotropic behaviour and the deterioration process of bitumen in fatigue test," Construction and Building Materials, vol. 101, pp. 277286, 2015.

[29] F. Pérez, R. Miró and A. Martínez, "Analysis of the fatigue process in bituminous mixes.," in Transportation Research Board. 86th Annual Meeting., Washington, 2007.

[30] H. Von Quintus, "Application of the Endurance Limit Premise in Mechanistic-Empirical Based Pavement Design Procedures.," in International Conference on Perpetual Pavements, Columbus, 2006.

[31] J. García, C. García, J. Buisson, C. Cortés and J. Potti, "Pavimentos de larga duración.," in VIII Congreso Nacional de Firmes., Valladolid, 2008.

[32] UNE-EN 12697-24, Bituminous mixtures - Test methods for hot mix asphalt - Part 24: Resistance to fatigue, 2013.

[33] T. Hou, S. Underwood and R. Kim, "Fatigue performance prediction of North Carolina mixtures using 
the simplified viscoelastic continuum damage model," Asphalt Paving Technology: Association of Asphalt Paving Technologists-Proceedings of the Technical Sessions, vol. 79, pp. 35-73, 2010.

[34] F. Haddadi, M. Ameri, M. Mirabimoghadam and H. Amiri, "Validation of a simplified method in viscoelastic continuum damage (VECD) model developed for flexural mode of loading," Construction and Building Materials, no. 95, pp. 892-897, 2015.

[35] F. Safaei, C. Castorena and Y. Kim, "Linking asphalt binder fatigue to asphalt mixture fatigue performance using viscoelastic continuum damage modeling," Mechanics of Time-Dependent Materials, vol. 20, no. 3, pp. 299-323, 2016.

[36] F. Pérez, G. Valdés, R. Botella, R. Miró and A. Martínez, "Approach to fatigue performance using Fénix test for asphalt concrete mixtures.," Construction and Building Materials, vol. 26, no. 1, pp. 372-380, 2012.

[37] F. Pérez, G. Valdés, R. Miró, R. Botella and J. Campana, "Effect of thermal stresses on fatigue behavior of bituminous mixes.," Transportation Research Record, vol. 4, no. 2210, pp. 90-96, 2011.

[38] R. Botella, F. Pérez, A. Martínez, R. Miró and J. Amorós, "Método de estimación de las leyes de fatiga de las mezclas bituminosas mediante el ensayo Ebade," in IX Jornada Nacional Asefma, Madrid, 2014.

[39] S. Tangella, J. Craus, J. Deacon and C. Monismith, "Sumary report on fatigue response of asphalt mixtures. Technical memorandum No. TM-UCB-A-003A-89-3M.," Institute of Transportation Studies, University of California., Berkeley, 1990.

[40] G. Valdes, A. Calabi, R. Miró and J. Norambuena, "Mechanical behavior of asphalt mixtures with different aggregate type," Construction and Building Materials, no. 101, p. 474-481, 2015. 



\section{FIGURES}

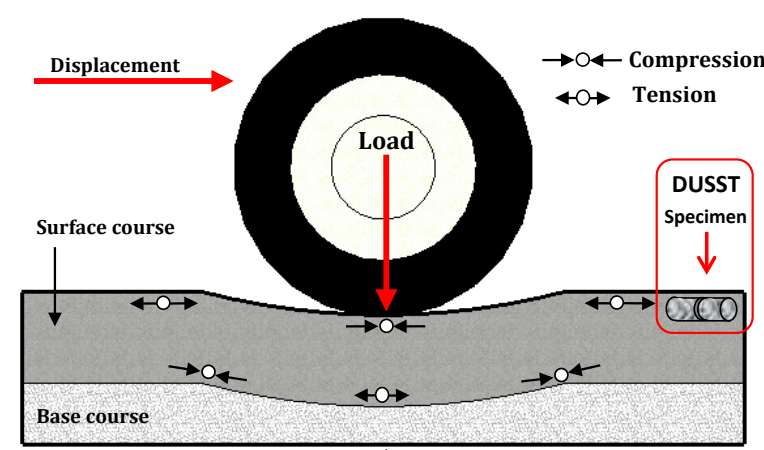

a)

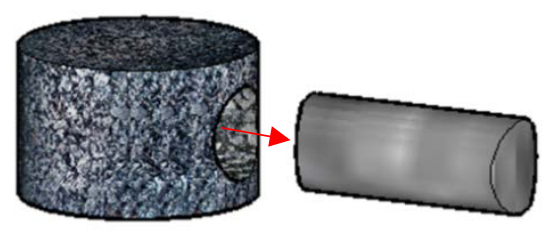

b)

Fig. 1 a) Stress state of the asphalt layers on a pavement and b) DUSST specimen manufacture scheme

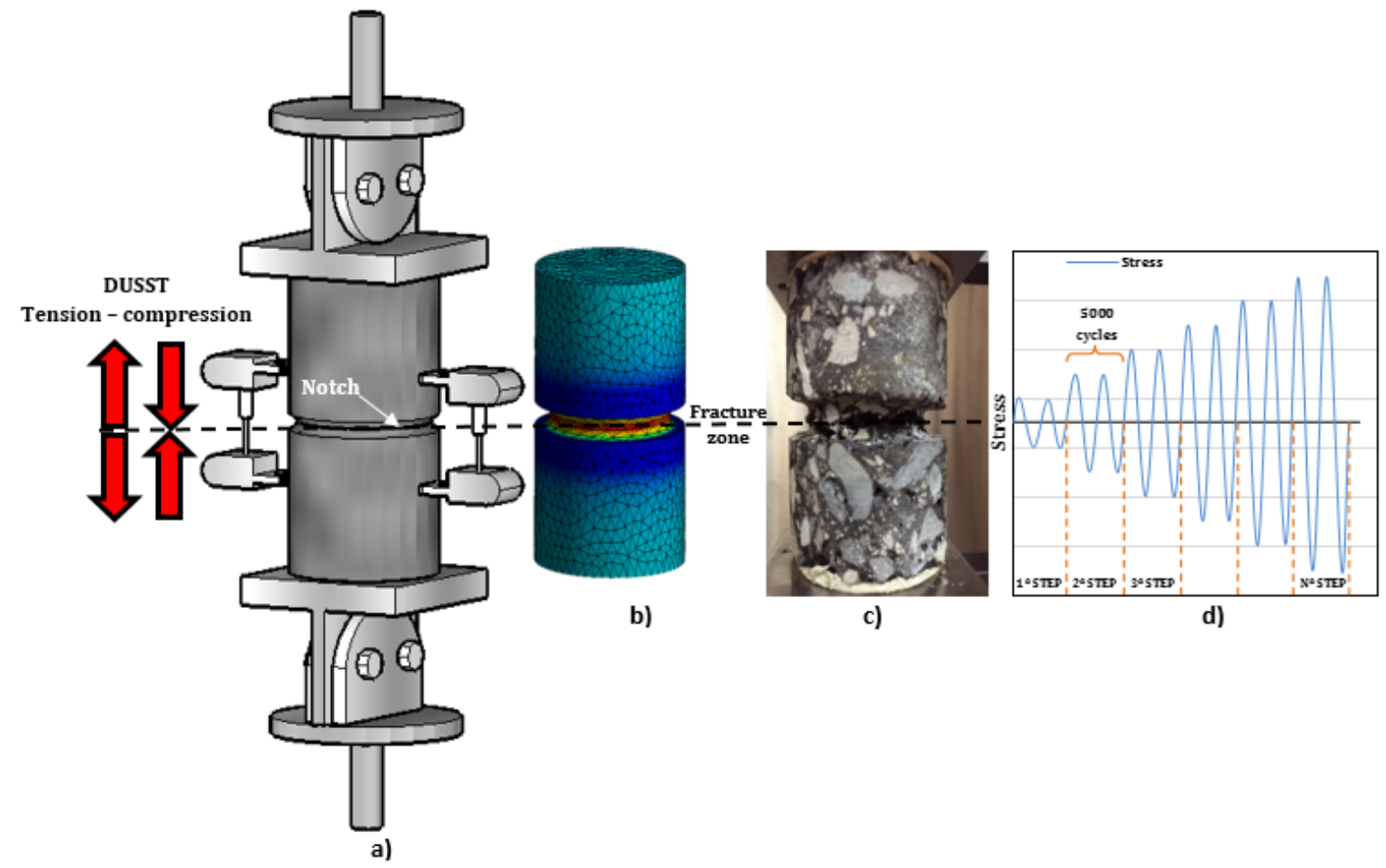

Fig. 2 a) DUSST test device, b) stresses simulation in the test specimen, c) fatigue cracking in the test specimen and d) sinusoidal stresses tension-compression applied to the specimen in DUSST procedure 


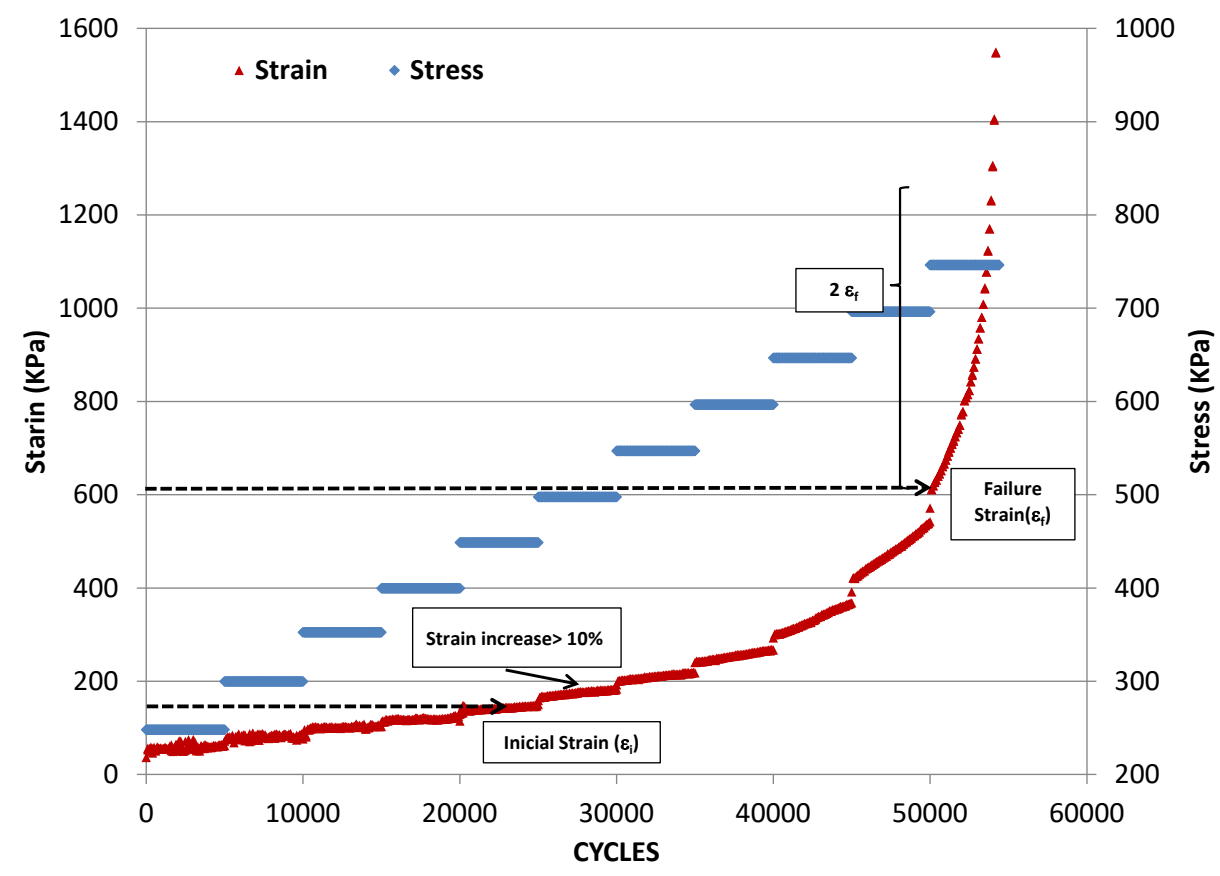

Fig. 3 Evolution of strains evaluated with DUSST procedure

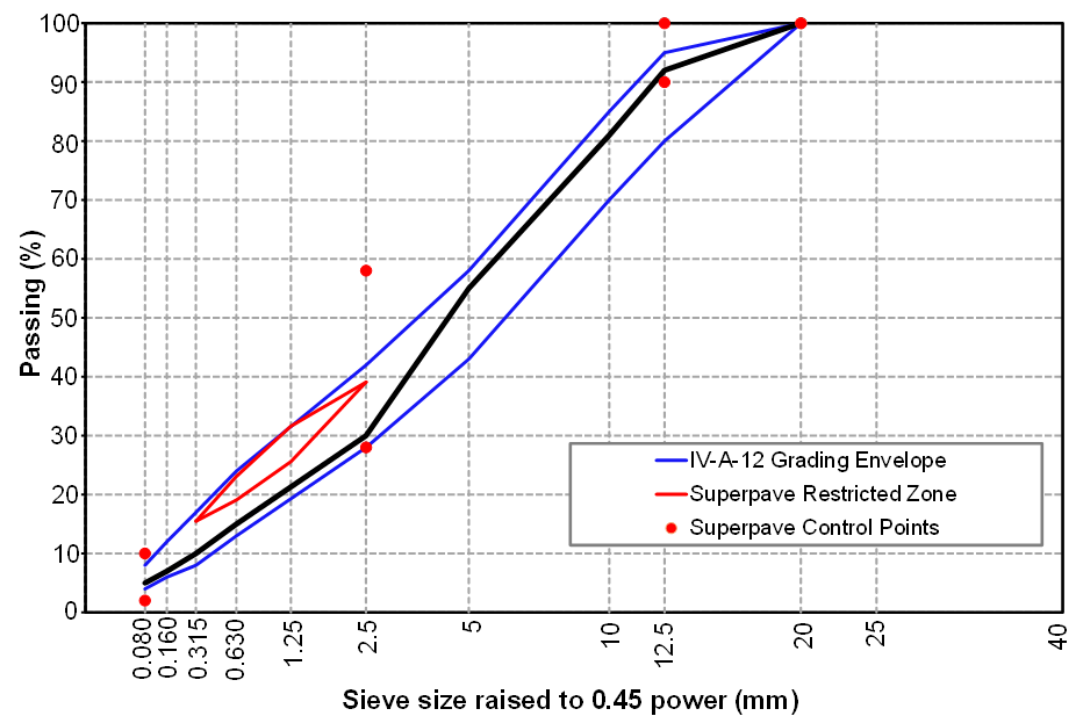

Fig. 4. Aggregate gradation of the IV-A-12 asphalt mixture. 


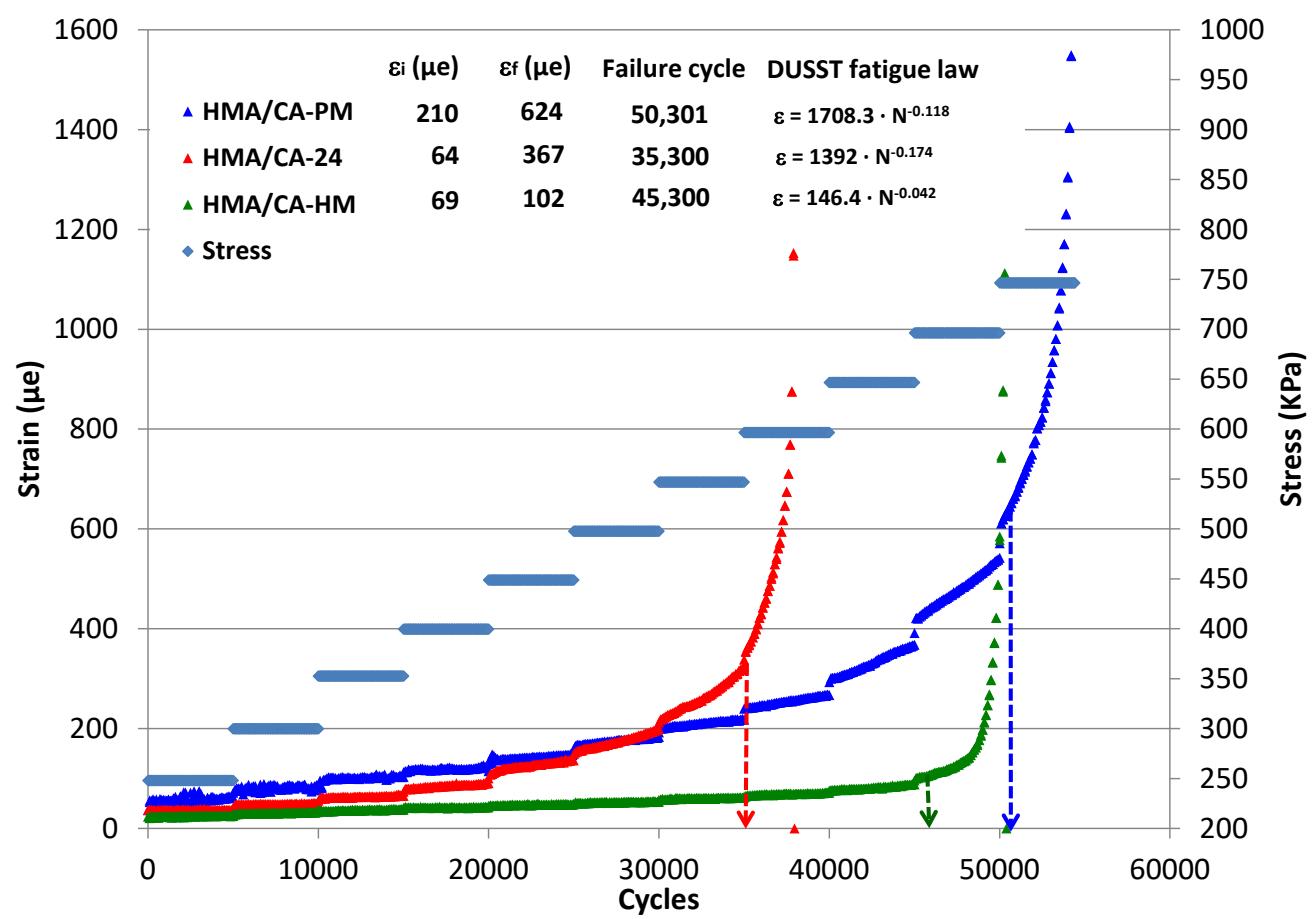

Fig. 5. Evolution of strains in asphalt mixtures with different type of bitumens.

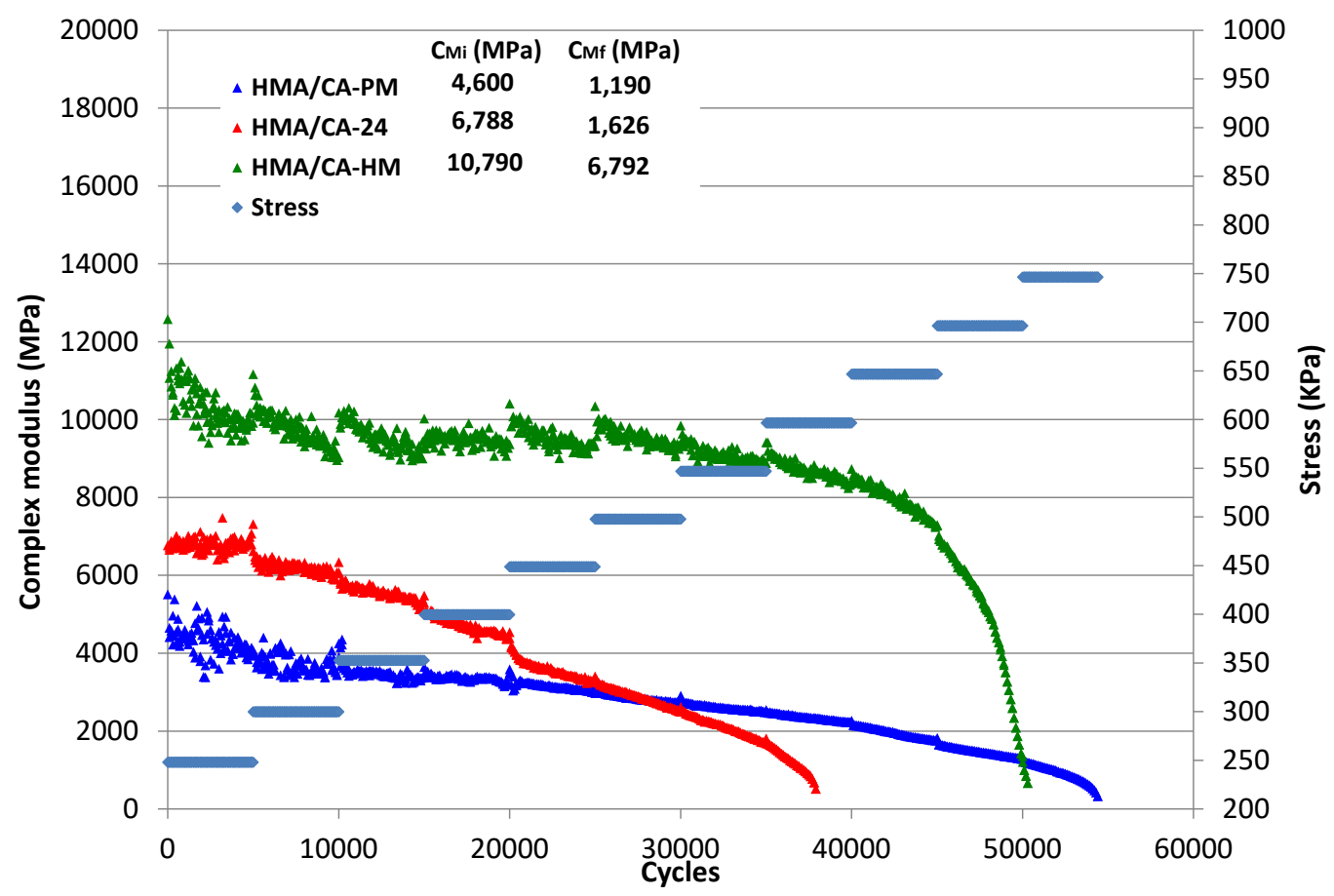

Fig. 6. Evolution of complex modulus in asphalt mixtures with different type of bitumens. 


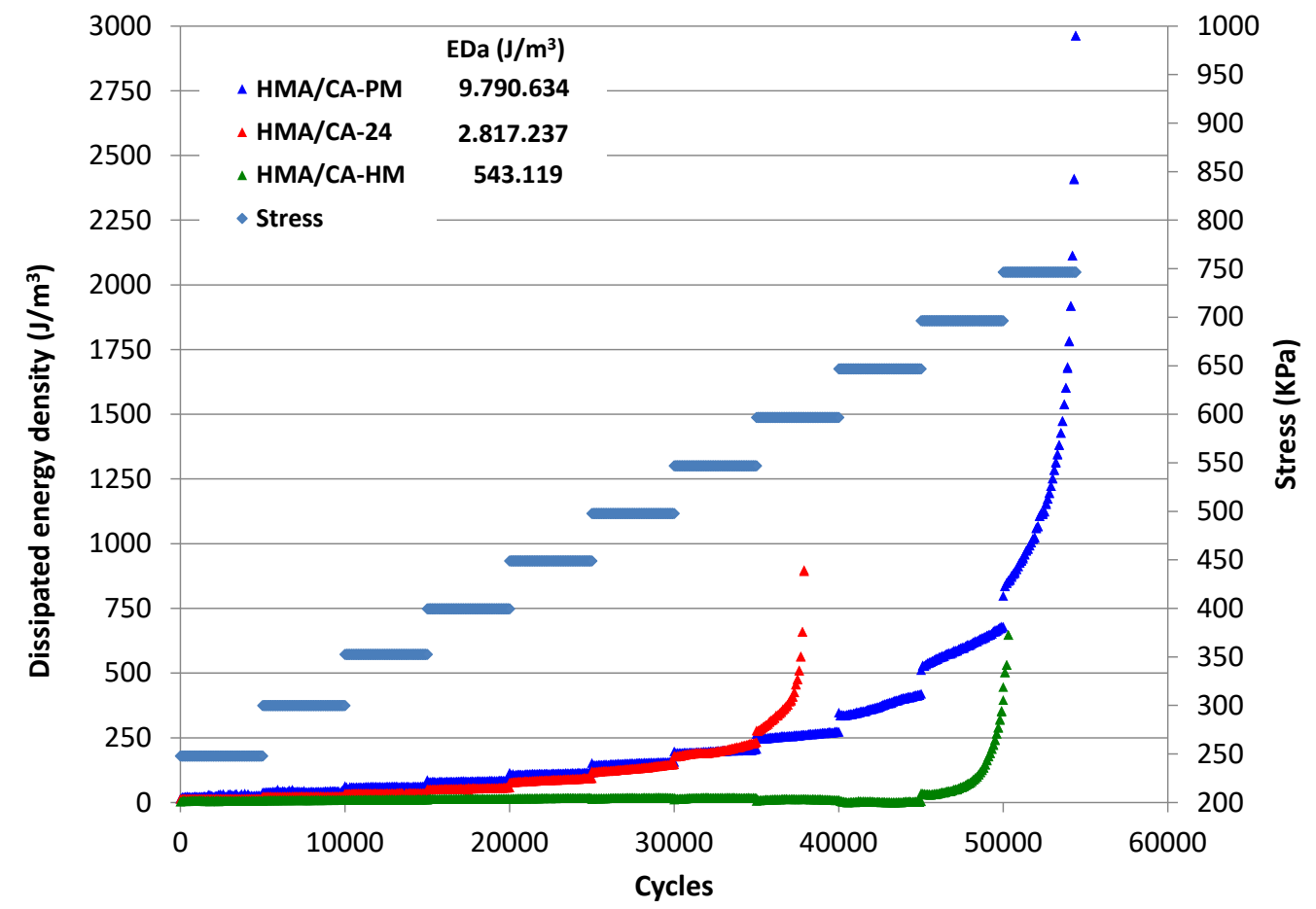

Fig. 7. Evolution of dissipated energy density in asphalt mixtures with different type of bitumens 


\section{TABLES}

Table 1. Properties of the bitumens.

\begin{tabular}{|c|c|c|c|c|c|c|}
\hline Tests & CA-24 & Esp. & CA-PM & Esp. & CA-HM & Esp. \\
\hline Absolute Viscosity at $60^{\circ} \mathrm{C}, 300 \mathrm{~mm} \mathrm{Hg}(\mathrm{P})$ & 3077 & Min 2400 & - & - & - & - \\
\hline Penetration at $25^{\circ} \mathrm{C}, 100$ g. 5 s. $(0.1 \mathrm{~mm})$ & 56 & Min 40 & 65 & $60-80$ & 14 & $12-17$ \\
\hline Softening Point R\&B, $\left({ }^{\circ} \mathrm{C}\right)$ & 51 & Informar & 76 & Min 60 & 65 & Min. 65 \\
\hline Ductility at $5^{\circ} \mathrm{C},(\mathrm{cm})$ & - & - & 52 & Min 50 & - & - \\
\hline Ductility at $25^{\circ} \mathrm{C},(\mathrm{cm})$ & $>150$ & 100 & 98 & Min 80 & - & - \\
\hline Penetration Index & -0.7 & $-1.5 a+1.0$ & 4.5 & Min +2 & -0.62 & Min. -1.5 \\
\hline Fraass Brittle Point, $\left({ }^{\circ} \mathrm{C}\right)$ & - & - & -18 & Max -17 & -3 & Max. -5 \\
\hline Elastic Recovery $\left(13^{\circ} \mathrm{C}, 20 \mathrm{~cm}, 1 \mathrm{hr}, \%\right)$ & - & - & 66 & Informar & - & - \\
\hline Cleveland Open Cup Flash Point, $\left({ }^{\circ} \mathrm{C}\right)$ & 332 & Min 232 & 240 & Min 235 & $>240$ & Min. 240 \\
\hline Brookfield Viscosity at $135^{\circ} \mathrm{C}$ (cP) & - & - & - & - & 1709 & Min. 1200 \\
\hline Brookfield Viscosity at $160^{\circ} \mathrm{C}(\mathrm{cP})$ & - & - & - & - & 453.3 & Min. 350 \\
\hline Spot test (\% xilol) & $<25$ & Max 30 & - & - & - & - \\
\hline Trichloroethylene solubility (\%) & 99.9 & Min 99 & - & - & - & - \\
\hline \multicolumn{7}{|l|}{ RTFOT } \\
\hline Mass Loss, (\%). & 0.00 & Max 0.8 & - & - & - & - \\
\hline Absolute Viscosity at $60^{\circ} \mathrm{C}, 300 \mathrm{~mm} \mathrm{Hg}(\mathrm{P})$ & 7475 & Informar & - & - & - & \\
\hline Ductility at $25^{\circ} \mathrm{C}, 5 \mathrm{~cm} / \mathrm{min},(\mathrm{cm})$ & 150 & Min 100 & - & - & - & - \\
\hline Durability Index & 2.4 & Max 3.5 & - & - & - & $\operatorname{Min} 55$ \\
\hline Retained Penetration, (\%) & - & - & - & - & 64 & Max 10 \\
\hline Softening Point R\&B Increase, $\left({ }^{\circ} \mathrm{C}\right)$ & - & - & - & - & 9 & IVIda .10 \\
\hline
\end{tabular}

Table 2. Properties of aggregates.

\begin{tabular}{lcccl}
\hline Tests & AC & AF1 & AF2 & Specifications \\
\hline Los Angeles Abrasion Loss (\%) & 25 & 16 & 15 & Máx. 25 (*)\% - 35\% \\
Crushed aggregates (\%) & 100 & 92 & 90 & Mín. 90\% (*) - 70\% \\
Flakiness index (\%) & 8 & 2,5 & 0 & Máx. 10\% (*) - 15\% \\
Specific gravity (kg/m3) & 2360 & 2630 & 2640 & - \\
Shape factor & 0.41 & 0.52 & 0.60 & \\
Coarse particle index & 14.4 & 14.5 & 12.6 & - \\
Fine particle index & 14.1 & 23.0 & 17.8 & - \\
Silica by SEM (\% weight) & 63.3 & 59.9 & 59.1 & - \\
\hline
\end{tabular}

$(*)$ Surface layer

Table 3. DUSST parameters of asphalt mixture manufactured with different type of aggregates.

\begin{tabular}{ccccccc}
\hline $\begin{array}{c}\text { Aggregate } \\
\text { Type }\end{array}$ & $\begin{array}{c}\boldsymbol{\varepsilon}_{\mathbf{i}} \\
\mathbf{\mu e})\end{array}$ & $\begin{array}{c}\boldsymbol{\varepsilon}_{\mathbf{f}} \\
\mathbf{( \mu e )}\end{array}$ & Failure Cycle & $\begin{array}{c}\left|\mathbf{E}^{*}\right|_{\mathbf{i}} \\
\mathbf{M P a})\end{array}$ & $\begin{array}{c}\left|\mathbf{E}^{*}\right|_{\mathbf{f}} \\
\mathbf{( M P a}\end{array}$ & $\begin{array}{c}\mathbf{D E D}_{\mathbf{a}} \\
\left(\mathbf{J} / \mathbf{m}^{\mathbf{3}}\right)\end{array}$ \\
\hline AF1 & 64 & 367 & 35,300 & 6,788 & 1,626 & $2,808,211$ \\
AF2 & 103 & 271 & 40,400 & 6,416 & 2,349 & $2,817,237$ \\
AC & 72 & 359 & 30,301 & 7,612 & 1,506 & $2,128,554$ \\
\hline
\end{tabular}


Table 4. Results of ANOVA for DUSST parameters

\begin{tabular}{|c|c|c|c|c|c|c|c|}
\hline $\begin{array}{l}\text { DUSST } \\
\text { Parameters }\end{array}$ & $\begin{array}{l}\text { Source of } \\
\text { Variation }\end{array}$ & SS & DF & MS & F-Value & P-Value & $\begin{array}{l}\text { Critical } \\
\text { F-Value }\end{array}$ \\
\hline \multirow{2}{*}{$\begin{array}{l}\text { Initial Strain } \\
\quad(\varepsilon i)\end{array}$} & Bitumen type & 41131.5556 & 2 & 20565.7778 & 160.53 & $6.174 \mathrm{E}-06$ & 5.1432 \\
\hline & Within groups & 768.666667 & 6 & 128.111111 & & & \\
\hline \multirow{2}{*}{$\begin{array}{l}\text { Failure Strain } \\
\qquad\left(\varepsilon_{\mathrm{f}}\right)\end{array}$} & Bitumen type & 408758 & 2 & 204379 & 33.57 & 0.00055228 & 5.1432 \\
\hline & Within groups & 36534 & 6 & 6089 & & & \\
\hline \multirow{2}{*}{$\begin{array}{c}\text { Complex } \\
\text { Modulus } \\
\left(\left|E^{*}\right|_{i}\right)\end{array}$} & Bitumen type & 59112653.6 & 2 & 29556326.8 & 37.43 & 0.00040867 & 5.1432 \\
\hline & Within groups & 4738326.67 & 6 & 789721.111 & & & \\
\hline \multirow{2}{*}{$\begin{array}{c}\text { Dissipated } \\
\text { Energy Density } \\
\left(\mathrm{DED}_{\mathrm{a}}\right)\end{array}$} & Bitumen type & $1.3932 \mathrm{E}+14$ & 2 & $6.9658 \mathrm{E}+13$ & 63.42 & $9.2135 \mathrm{E}-05$ & 5.1432 \\
\hline & Within groups & $6.59 \mathrm{E}+12$ & 6 & $1.0983 \mathrm{E}+12$ & & & \\
\hline \multirow{2}{*}{$\begin{array}{l}\text { Initial Strain } \\
\quad(\varepsilon i)\end{array}$} & Aggregate type & 2577.555556 & 2 & 1288.777778 & 6.12 & 0.035584317 & 5.1432 \\
\hline & Within groups & 1263.333333 & 6 & 210.5555556 & & & \\
\hline \multirow{2}{*}{$\begin{array}{l}\text { Failure Strain } \\
\qquad\left(\varepsilon_{\mathrm{f}}\right)\end{array}$} & Aggregate type & 17146.8889 & 2 & 8573.44444 & 5.82 & 0.0393694 & 5.1432 \\
\hline & Within groups & 8840.66667 & 6 & 1473.44444 & & & \\
\hline \multirow{2}{*}{$\begin{array}{c}\text { Complex } \\
\text { Modulus } \\
\left(\left.\mathrm{E}^{*}\right|_{\mathrm{i}}\right)\end{array}$} & Aggregate type & 2246429.56 & 2 & 1123214.78 & 2.59 & 0.15485535 & 5.1432 \\
\hline & Within groups & 2605484.67 & 6 & 434247.444 & & & \\
\hline \multirow{2}{*}{$\begin{array}{l}\text { Dissipated } \\
\text { Energy Density } \\
\left(\mathrm{DED}_{\mathrm{a}}\right)\end{array}$} & Aggregate type & $9.363 \mathrm{E}+11$ & 2 & $4.6815 \mathrm{E}+11$ & 5.71 & 0.0409239 & 5.1432 \\
\hline & Within groups & $4.9231 \mathrm{E}+11$ & 6 & $8.2052 \mathrm{E}+10$ & & & \\
\hline
\end{tabular}

